Psicologia: Ciência e Profissão

JAN/MAR. 2016, VOL.36 No 1, 101-115.

DOI: 10.1590/1982-3703000092014

\title{
The L Word - Discussões em torno da parentalidade lésbica
}

\author{
Carine Valéria Mendes dos Santos \\ Universidade de São Paulo, SP, Brasil.
}

\author{
Isabel Cristina Gomes \\ Universidade de São Paulo, SP, Brasil.
}

Resumo: Este artigo busca empreender uma reflexão crítica acerca dos modelos de família implicados na construção da parentalidade lésbica, tendo como referenciais teóricos a psicanálise e os estudos psicossociais na perspectiva de gênero. Tomando-se as redefinições do conceito de família que não se restringem mais ao modelo tradicional heterossexual, casais homoafetivos estão buscando seus direitos conjugais e homoparentais, se situando em um novo paradigma interrelacional que preconiza a filiação afetiva em substituição à vinculação consanguínea. Por meio da análise de conteúdo de alguns episódios de uma série televisiva norte-americana, referente a um casal de lésbicas, elaborou-se um estudo qualitativo da temática em duas categorias: processos de viabilização parental e a influência do modelo de família heteronormativo na construção da parentalidade lésbica. Concluiu-se que, no material em questão, o processo de filiação das personagens estava atrelado no início predominantemente aos processos biológicos de reprodução, no entanto, o exercício parental possibilitou a emergência de um novo modelo familiar caracterizado pela comaternidade. As novas configurações familiares muitas vezes encerram à sua volta um paradoxo: o novo sendo vivido pela repetição da tradição, o que nos leva às influências das heranças geracionais.

Palavras-chave: Poder familiar, Homosexualidade Feminina, Família.

\section{The L Word - Debats on lesbian parenting}

Abstract: This paper carries out a critical discussion about family models related to lesbian parenthood construction, using psychoanalysis and psychosocial studies in gender perspective as theoretical approaches. Taking under consideration recent redefinitions on the concept of family, not limited anymore to the traditional heterosexual standard, homosexual couples are claiming for their rights as spouses and parents, turning the paradigm's focus on affective interrelations instead of on blood bounds. The content analysis approach used in some episodes of an American television series concerning lesbian parenthood made it possible to develop a qualitative study focusing on two categories: parenthood feasibility processes and heteronormative influences on lesbian parenthood construction. The conclusion shows that bounds between characters were at first and predominantly based on biological reproductive processes, although a new family model characterized by the co-motherhood has emerged. New familiar sets have presented a paradox: new family models repeat traditional models, and that takes us to generational inheritance influences.

Keywords: Parenting, Female Homosexuality, Family. 


\title{
The L Word-Discusiones en torno a la parentalidad lésbica
}

\begin{abstract}
Resumen: Este artículo busca emprender una reflexión crítica sobre los modelos de familia involucrados en la construcción de la parentalidad lésbica, asumiendo como referenciales teóricos: el psicoanálisis y los estudios psicosociales en la perspectiva de género. Asumiendo redefiniciones del concepto de familia que ya no se limitan al modelo tradicional heterosexual, parejas homoafectivas están buscando sus derechos conyugales y homoparentales, situándose en un nuevo paradigma interrelacional que defiende la filiación afectiva en sustitución de la vinculación consanguínea. Por medio del análisis de contenido de algunos episodios de una serie de televisión estadunidense que trata sobre una pareja lésbica, se realizó un estudio cualitativo de temática mencionada en dos categorías procesos de facilitación parental e influencia del modelo de familia heteronormativa en la construcción de la parentalidad lésbica. Se concluyó que en el material empleado el proceso de filiación de los personajes estaba ligado, en principio y predominantemente, a los procesos biológicos de reproducción, aunque ha surgido un nuevo modelo de familia caracterizado por la co-maternidad. Las nuevas configuraciones familiares a menudo encierran una paradoja: lo nuevo está siendo vivido por la repetición de la tradición, lo que nos lleva a las influencias de herencias generacionales.
\end{abstract}

Palabras clave: Responsabilidad parenteral, Homosexualidad ferminina, Família.

\section{Novas configurações familiares - famílias possíveis}

A título de contextualização, quando abordamos as novas configurações familiares da atualidade, é necessário, primeiramente, nos remetermos às origens do status de novidade atribuído a essas famílias. Nesse sentido, a família nuclear, que não existiu desde sempre, mas que atingiu seu lugar de tradição e modo privilegiado de ser, é ainda referência e modelo.

O casal constituído pelo homem e pela mulher, que, por meio da reprodução biológica gera seus filhos, legitimado pelo casamento como modelo ideal de família, estabeleceu-se ao longo de gerações ganhando sua condição natural. Assim, a família heterossexual nuclear tem uma história que a privilegia e garante a sua soberania como lugar de transmissão e reprodução social, cultural e histórica (Hollekim, Slaatten, \& Anderssen, 2012).

Os privilégios da família heterossexual determinam padrões de predominância no que diz respeito às concepções de cultura, sexo e corpo. Estes padrões instituem normas sociais reguladoras em relação às práticas sexuais, constituindo o que pode ser chamado de uma heteronormatividade. De acordo com Miranda (2010), “Os padrões normativos já estão tão enraizados na sociedade que não há, na maioria das vezes, crítica e questionamento acerca deles. São tidos como verdades e reforçados pelos discursos científico/biomédico, religioso e do senso comum" (p. 86). Sobre o conceito de heteronormatividade, Foster (2001) o define como:

\footnotetext{
Por heteronormatividade, entende-se a reprodução de práticas e códigos heterossexuais, sustentada pelo casamento monogâmico, amor romântico, fidelidade conjugal, constituição de família (esquema pai-mãe-filho(a)(s)). Na esteira das implicações da aludida palavra, tem-se o heterossexismo compulsório, sendo que, por esse último termo, entende-se o imperativo inquestionado e inquestionável por parte de todos os membros da sociedade com o intuito de reforçar ou dar legitimidade às práticas heterossexuais (p. 19).
}

Compreendendo a heteronormatividade como imperativo enraizado culturalmente atuando em prol da preservação do status quo, é possível afirmar que esta norma estabelece relações hierarquizadas com outros tipos de práticas sexuais e, consequentemente, levando-se a considerar como desviantes outros tipos de configurações familiares (Miranda, 2010). Desse modo, o modelo familiar heteronormativo se encontra numa posição favorecida sustentada pela opressão ou ilegitimidade de outros arranjos familiares. É o que também nos explicita Butler (2003) ao tratar da indissociabilidade derivativa entre parentesco e heterossexualidade: 


\section{Dos Santos, Carine Valéria Mendes; Gomes, Isabel Cristina (2015). The L Word - Discussões EM TORno da PARENTALIDAde lésbica}

Variações no parentesco que se afastem de formas diádicas de família heterossexual garantidas pelo juramento do casamento, além de serem consideradas perigosas para as crianças, colocam em risco as leis consideradas naturais e culturais que supostamente amparam a inteligibilidade humana (p. 224).

Mudanças vieram acontecendo no cerne do modelo tradicional de família, como a inserção da mulher no mercado de trabalho, o controle de natalidade possibilitado pelas técnicas contraceptivas, o aumento do número de divórcios e a consequente possibilidade de novas uniões, o surgimento de novas tecnologias reprodutivas e o declínio do patriarcado. Essas mudanças repercutem do paradigma vigente -0 modelo familiar heteronormativo, abrindo passagem para uma nova conceituação de família que, de acordo com Rodriguez e Paiva (2009), se amplia, passando a abranger "um conjunto de indivíduos ligados entre si por uma aliança permeada por afetos, que podem ou não possuir um vínculo consanguíneo" (p. 17).

Para Rodriguez e Paiva (2009), há uma ampliação também das possibilidades de constituições familiares, que adquirem maior flexibilidade e fronteiras menos estanques. Desse modo, é possível falar em novas formas relacionais que caminham no sentido do afastamento ou aproximação do modelo de família tradicional (nuclear, monogâmico, heterossexual), a saber: as famílias reconstituídas que englobam uniões onde o casal já tem filhos(as) de outras relações anteriores, famílias monoparentais que se constituem por uma mãe ou um pai e seus filhos, famílias homoparentais ${ }^{1}$ constituídas por casais de gays ou lésbicas e seus filhos (Rodriguez, \& Gomes, 2012) e casais sem filiação (Rios, \& Gomes, 2009).

Dentre essas configurações, no que se refere às mudanças no contexto da família homoparental, podese mencionar a aprovação do casamento civil por casais homossexuais em países como Holanda, Espanha, Canadá e Argentina (Corrêa, 2012), sendo também aprovado em 2013, pelo Reino Unido e França ${ }^{2}$. No Brasil, especificamente em São Paulo, a CorregedoriaGeral da Justiça do Estado, em dezembro de 2012, pu- blicou uma norma que dá aos casais gays a igualdade dos procedimentos (exigidos para casais heterossexuais) necessários para a efetivação do casamento civil ${ }^{3}$.

Em meio à repercussão dessas mudanças para a estruturação da família contemporânea, Butler (2003) tenta esclarecer que, mesmo dentro da ilegitimidade, existiriam distinções táticas e tácitas entre vidas homossexuais mais ou menos legítimas, ou seja, o casal homossexual estável e que deseja constituir família seria mais elegível a alcançar uma legitimidade futura se comparado a outros agentes sexuais que vivem fora dos parâmetros construídos dentro da esfera do casamento. Logo, existiria uma relação hierárquica dentro da própria ilegitimidade da comunidade gay estabelecendo graus diferenciados de exclusão de acordo com a proximidade com os parâmetros normativos do casamento.

Numa relação de complementaridade ao argumento acima apresentado pela autora, retoma-se o pressuposto elaborado por Roudinesco (2003) de que o desejo pelo reconhecimento da vinculação através do casamento e também da filiação manifestado pelos homossexuais está associado ao desejo de normatividade. Desejo este que se pauta e é balizado pela norma predominante heterossexual, mas que, no entanto, transgride e reinventa os fundamentos que sustentam as representações erigidas em relação a noção e ao estatuto da família. Sobre essa conjuntura, Passos (2005) aponta:

Estamos, com isso, propondo que as novas formas de ser família hoje sejam consideradas a partir de uma ética que leve em conta as demandas afetivas dos sujeitos nelas envolvidos. Esta ética deve estar assentada, portanto, nas diferentes formas de conjugalidade, parentalidade e filiação que configuram um contexto familiar baseado nos laços de afeto. Seus princípios adviriam não mais das leis gerais que fundamentam a ordem familiar patriarcal, mas das novas redes que sustentam as relações de afeto nas novas famílias. Isto significa dizer que ela está sendo reconstruída permanentemente a partir das expressões relacionais que se diferenciam, repercutindo no contexto da sociedade mais ampla, ao mesmo tempo em que são marcadas pelas tramas sociais (pp. 33-34).

1. O termo homoparentalidade foi criado em Paris pela Associação de Pais e Futuros Pais Gays e Lésbicas (PPGL) em 1997. O termo define a situação na qual um adulto homossexual é, ou pretende ser, pai/mãe (Homoparentalidade, 2014).

2. A esse respeito, consultar notícia veiculada no sítio: COM aval de rainha Elizabeth II, casamento gay é aprovado no Reino Unido. opera mundi, 17 jul. 2013. Disponível em: <http://operamundi.uol.com.br/conteudo/noticias/30064/com+aval+de+rainha+elizabeth+ii+casamento+gay+e+aprovado+no+reino+unido.shtml>

3. Consultar: BEDINELLI, T. SP deixa de exigir autorização para casamento gay. Folha de São Paulo, Cotidiano. Disponível em: <http:// wwwl.folha.uol.com.br/fsp/ cotidiano/96498-sp-deixa-de-exigir-autorizacao-para-casamento-gay.shtml> 
É a partir dessa nova ética afetiva, responsável por desconstruir estereótipos dentro do contexto familiar, que podemos falar em um novo paradigma a ser construído. Um paradigma que englobe arranjos possíveis em detrimento de uma pretensa noção de família pré-determinada e universal.

Pensando nessas considerações, este artigo se detém na seguinte questão: Quais as possibilidades de ser família para os casais homossexuais femininos, cuja especificidade permite a reiteração da parentalidade biológica, todavia exercida de um modo novo? Essa mesma questão será ilustrada e explorada a partir da análise da construção parental em um casal de lésbicas, numa série televisiva norte-americana.

\section{Percurso metodológico}

\section{The L Word}

No ano de 2004 teve início a transmissão, pela televisão a cabo, da série criada por Ilene Chaiken, The $L$ Word. A série, que durou seis temporadas e teve seu término no ano de 2008, conta a história de um grupo de lésbicas que mora em Los Angeles, Califórnia. Neste artigo optou-se pela apresentação da temática da parentalidade lésbica, bem como de alguns aspectos correlacionais que serão ilustrados a seguir, como: homossexualidade, conjugalidade homoafetiva, preconceito, aceitação familiar, adoção e inseminação artificial (The L Word, 2012).

\section{Participantes}

Almejando promover uma reflexão crítica sobre os modelos de família implicados na construção da parentalidade lésbica, este artigo tomará como objeto para tal finalidade as situações vivenciadas pelo casal Bette e Tina, personagens da série acima referida, em torno dessa constituição parental.

Por conseguinte, nessa reflexão considerou-se o entendimento da série como um recurso midiático capaz de veicular representações e significados referentes ao contexto homossexual, enfatizando aqui as relações parentais de um casal lésbico inserido na cultura norte-americana. A série situa as diversas tramas de seu enredo na cidade de Los Angeles e, apesar de tratar-se de situações fictícias, é possível refletir sobre a emergência de discursos e significados que caracterizam as relações homoafetivas, os novos arranjos familiares da contemporaneidade e suas diversas problemáticas peculiares.
Seguindo esse raciocínio, Miranda (2010) afirma que "Toda a produção cultural se baseia em representações coletivas que circulam na sociedade e que, de alguma forma, estão relacionadas ao imaginário de uma época" (p. 82). Logo, a produção de uma série que trata predominantemente da temática homossexual apresenta a assunção de representações que transcendem o imaginário coletivo construído em torno dos referenciais heteronormativos. Vale ressaltar que a mídia televisiva brasileira ultimamente tem trazido à tona a questão dos relacionamentos homoafetivos, talvez, como um primeiro passo para futuramente discutir de forma mais ampla a homoparentalidade. Sobre as novas subjetividades veiculadas a partir da cultura midiática, a autora acima destaca:

\footnotetext{
A leitura dos produtos culturais nos permite perceber os valores dominantes de nosso tempo e observar que esta cultura midiatizada inaugura novas subjetividades; diferentes percepções de espaço, tempo e realidade; múltiplas e instáveis identidades e novos agenciamentos políticos e econômicos que forçam o indivíduo a aprender a conviver com uma imensa fragmentação e proliferação de imagens que formam a rede de significações de seu cotidiano (Miranda, 2010, pp. 81-82).
}

Nesse ínterim, os recursos midiáticos podem servir tanto para preservar o discurso heteronormativo quanto para trazer à tona novos discursos construídos a partir do referencial homossexual e desconstruir dicotomias hierarquizadas que determinam a oposição entre heterossexualidade e homossexualidade.

\section{Instrumentos de pesquisa}

Inicialmente, a totalidade dos episódios das temporadas da série The L Word serviu como instrumento de investigação. No entanto, para a análise das situações representadas pelo casal Bette e Tina e, considerando a constituição parental como o critério de seleção pré-definido tanto na escolha da série como dos recortes empreendidos, foram selecionadas algumas cenas apresentadas em: nove episódios da $1^{\text {a }}$ temporada, sete episódios da $2^{\text {a }}$ temporada e cinco episódios da $3^{\mathrm{a}}$ temporada (The LWord, 2012).

\section{Procedimentos de coleta e análise do material}

Utilizou-se para a seleção e análise do material pesquisado o método da análise de conteúdo desen- 


\section{Dos Santos, Carine Valéria Mendes; Gomes, Isabel Cristina (2015).}

The L Word - Discussões EM TORNo da PARENTALIDAdE LÉSBiCa

volvido por Bardin (1977/2009) que analisa a comunicação levando em conta o conteúdo das mensagens, as pessoas implicadas na comunicação e o efeito dessas mensagens situadas em um contexto. A análise de conteúdo permitiria a construção de inferências e interpretações a partir do conteúdo analisado, por meio das seguintes fases de execução: exploração do material e determinação das unidades de análise e categorização (Bardin, 1977/2009; Campos, 2004).

Dessa forma, os recortes realizados tiveram o intuito de demonstrar aspectos significativos que se relacionavam à parentalidade lésbica, definida ao longo da investigação da série como unidade de análise temática geral. A partir dessa exploração, optou-se por destacar como unidade de análise temática específica o processo inicial de constituição parental das personagens Bette e Tina. Tendo como embasamento o referencial psicanalítico de casal e família, incluindo a psicanálise vincular argentina e o conceito de transmissão psíquica de Kaes (1993/2001), assim como os estudos psicossociais na perspectiva de gênero, as unidades de análise (geral e específica), deram origem à divisão em duas categorias, elaboradas e discutidas qualitativamente, a saber: processos de viabilização parental e influências do modelo heteronormativo para a parentalidade lésbica.

\section{Bette e Tina}

Na série, Bette Porter era uma renomada diretora de um Museu de Artes em Los Angeles e Tina Kenard uma empresária do ramo cinematográfico. $\mathrm{O}$ casal formado pelas personagens estava junto há sete anos quando resolvem tentar ter um bebê através da inseminação artificial. Tina é aquela que passaria pelo processo da gestação e Bette a que proveria os recursos necessários para a viabilização financeira desse processo, além de ser o suporte emocional e protetor de Tina. Sobre esta divisão de atribuições, Tina em um episódio da $1^{\text {a }}$ temporada afirma "Eu larguei meu emprego. Eu era uma executiva de sucesso crescente. Agora eu quero relaxar e preparar meu corpo para a gravidez. É isto o que estou fazendo. Estou pronta para começar uma família".

À semelhança dos casais heterossexuais tradicionais, Bette e Tina repetem o modelo de complementaridade conjugal: ativo-masculino/passivo-feminino, mesmo dentro da igualdade de gêneros, o que leva a supor a forte influência dos modelos das famílias de origem ou dos legados geracionais na constituição da conjugalidade ou família atual (Gomes, 2013). Bette e Tina, como muitos casais homoafetivos atuais, descendem de famílias hetero, o que nos faz pensar sobre a importância desse modelo relacional no estabelecimento e dinâmica de funcionamento do par lésbico e na necessidade de formarem uma família, reproduzindo o hegemonicamente esperado, inclusive por se tratar de duas mulheres.

No início da $1^{\text {a }}$ temporada, ocorre a procura pelo doador, um homem que correspondesse às expectativas de ambas. Em meio às dificuldades dessa busca e considerando o fato de que Tina seria a mãe gestante, ambas decidem tentar a inseminação com o sêmen de um doador afro-americano para que Bette - que tem descendência negra - se sinta identificada com o bebê.

Em uma das cenas em que as personagens conversam sobre as características genéticas do doador, Bette expõe o seguinte trecho de fala: "Logo no começo dissemos que se você fosse a mãe biológica consideraríamos um doador afro-americano, assim a criança pareceria mais nossa". Bette acha então aquele que ela denomina de "doador perfeito" e Tina vai com este ao Centro de coleta de sêmen, onde o mesmo apresenta seu atestado constando que não possui doenças sexualmente transmissíveis. Na primeira tentativa de inseminação, Tina engravida. Em uma das cenas, ainda dessa temporada, o pai de Bette, que se encontra com o casal para um jantar, recebe a notícia de que ambas teriam um bebê e sua reação é manifestada na seguinte fala: "Isto é biologicamente impossivel. A menos que tenha ocorrido um grande avanço na medicina que eu não saiba, a possibilidade que esta criança venha a ser meu neto não existe! Assim, estou feliz se é isso que você quer em sua amizade com a Srta. Kennard. Mas, na realidade não pode me pedir pra participar desta ficção de sua criação" (Melvin - pai de Bette).

É possível perceber neste trecho de fala que tanto a relação entre o casal quanto a parentalidade almejada por ambas é negada pelo pai de Bette, em função do reconhecimento da impossibilidade biológica de duas mulheres gerarem uma criança. Diante da realidade dessa limitação exposta por Melvin, Tina tenta argumentar o fato da seguinte forma: "Bette e eu passamos por tanta coisa para chegarmos até aqui. Temos discutido sobre como nosso filho poderia verdadeiramente refletir quem somos, mesmo limitadas pela biologia. Por isto decidimos por um doador afro-americano. Assim, quando olharmos para o nosso filho e você olhar para o seu neto, estaremos todos olhando para um rosto fami- 
liar" (Tina). Ao que Melvin ironiza: “Um homem negro é o pai desta criança? Um afro-americano. E por causa disso eu devo supostamente me sentir ligado a esta criança? Por que todos nós negros estamos de certa forma conectados? Nossos antepassados pertencem todos a alguma tribo na África, onde viviam batendo tambores! Isto é um absurdo!' (Melvin).

Nos segmentos de fala citados anteriormente, surge a temática da parentalidade e da filiação, ainda sob a égide da heteronormatividade, sendo questionadas e estigmatizadas. O uso das técnicas de reprodução assistida permitindo que um casal de mesmo sexo possa ter um filho confirma a utopia do diferente; como algo desconhecido que é logo rechaçado, desde o ambiente familiar mais próximo. Isso gera exposição, fragilidade e conflito nos envolvidos, dificultando o processo de parentificação ${ }^{4}$.

Mesmo com a preparação para a chegada do bebê, na qual nomes e sobrenomes foram discutidos, as personagens se inseriram em uma terapia de grupo com casais e roupas foram compradas, após o terceiro mês de gestação, Tina acaba abortando espontaneamente. Esse fato causa uma crise no relacionamento e um distanciamento entre o casal, o que, após uma traição de Bette, culmina em uma separação conjugal.

Observa-se que, no projeto do casal em torno da parentalidade gestada, as personagens, principalmente Bette que se apropria do papel de provedora e de suporte protetor familiar, não conseguem resistir à perda idealizada do futuro bebê. Pode-se inferir, pelas atitudes manifestas do casal que a dificuldade de elaboração do luto e o consequente distanciamento emocional decorrente dessa situação transformam o projeto da parentalidade num elemento de crise conjugal. Com isto, é possível pensar que a criança, para o casal, foi gerada no intuito de ascender ao status de família. Sem um bebê para alcançar o êxito desse desejo, a existência conjunta encontra um impasse que leva o relacionamento a uma ruptura temporária após a traição de Bette.

No final da primeira temporada, Tina volta a trabalhar, inicialmente em uma ONG e, na terceira temporada, ela retorna ao ramo cinematográfico como produtora. Após o rompimento do casal e a saída de Tina de casa, descobre-se que esta havia feito uma segunda inseminação antes da separação e estava grávida novamente. Bette pede que Tina a deixe fazer parte da vida do bebê, pois este foi concebido enquanto elas ainda estavam juntas, portanto, considera-o também como seu. Após refletir por um tempo, Tina acaba permitindo que Bette tenha o direito de participar da vida da criança. Bette então, à medida que vai construindo um quarto para o bebê em sua casa, passa a acompanhar todo o processo da gestação. Nesse momento, observa-se a flexibilidade das ex-parceiras em constituir outro arranjo familiar, típico das famílias reconstituídas, para desfrutarem do convívio com a futura criança.

Ocorre, nesse momento, uma reaproximação entre o casal e as personagens reatam o relacionamento pouco antes do nascimento do bebê, que é uma menina e recebe de Tina o nome de Angélica. Bette participa do parto e é ela quem corta o cordão umbilical. Após o nascimento de Angélica segue-se o período da maternagem inicial da criança, cujos cuidados são exercidos por ambas as mães (mamy Ti e mamy $\mathrm{Be}$ - nomes utilizados pelas personagens para que a criança reconheça a existência de duas mães em seu contexto familiar, o Ti e o Be seriam os elementos que estabeleceriam referenciais maternos diferenciados). Bette e Tina, por força do vivido, tentam se fixar nas posições de duas mães cuidadoras ou cocuidadoras, dessa forma começando a distanciar-se do modelo heteronormativo, movimento que possibilitará o início da construção de um novo modelo familiar próprio da homoparentalidade?

Constata-se, ao longo desses cuidados, uma ausência de participação das famílias biológicas extensivas das personagens, excetuando-se a irmã de Bette (Kit) que participa ativamente da educação e dos cuidados de Angélica. Como exemplo dessa não participação, segue-se a fala de David (filho de Kit e sobrinho de Bette) para justificar a distância do convívio com as personagens e Angélica: "Não apoio a adoção por homossexuais. Uma criança é melhor criada por uma mãe e um pai. E ela vai sofrer mais tarde, na falta de valores familiares tradicionais". No entanto, é possível perceber que o grupo de amigas em comum se mostra bastante participativo na vida do bebê e nos cuidados que lhe são oferecidos, atuando como possíveis substitutas dos familiares biológicos. Paralelamente a essa maternagem inicial, dá-se andamento ao processo de

4. Termo cunhado por Houzel para denominar o complexo processo de "tornar-se pais", implicando níveis conscientes e inconscientes do funcionamento mental. 


\section{Dos Santos, Carine Valéria Mendes; Gomes, Isabel Cristina (2015).}

The L Word - Discussões EM TORNo da PARENTALIDAdE LÉSBiCa

adoção de Angélica por Bette, processo este o qual ela tem que se submeter por não ser a mãe biológica.

Se por um lado constatamos a dificuldade e/ou preconceito de algumas famílias em aceitar as escolhas homoafetivas envolvendo algum elemento do grupo, embora considerando a diferença entre as culturas norte-americana e brasileira, cujo apego à família extensa é maior na segunda, percebemos a intenção na série de abordar o fato e pesquisas brasileiras realizadas com essa população (Moris, 2008; Noda, 2005) também confirmam a presença desses preconceitos familiares. Por outro lado, observamos a complexidade que se instala na construção desse tipo de parentalidade que envolve o uso de técnicas de reprodução assistida (doação de sêmen) associada a um processo de adoção legal, para que ambas efetivamente assumam o lugar de mães.

Os recortes citados trazem informações acerca de aspectos presentes na construção e no exercício da parentalidade lésbica em relação ao casal Bette e Tina e suscitam algumas reflexões que serão exploradas ao longo das categorias de análise.

\section{Categoria 1 - Parentalidade lésbica $x$ processos de viabilização}

Para dar início à análise dos processos de viabilização parental será preciso destacar a categorização elaborada por Zambrano (2006) no que diz respeito aos elementos constituintes dos laços familiares responsáveis por estabelecer ligações entre um adulto e uma criança, a saber: o vínculo biológico, referente à ligação genética entre os pais e a criança; o parentesco, referente à relação de pertencimento do indivíduo a um grupo determinado e formador de uma genealogia; a filiação, referente ao vínculo social reconhecido juridicamente pelas leis instituídas em determinada sociedade da qual o adulto e a criança fazem parte; e a parentalidade, referente ao exercício parental e cuidados cotidianos decorrentes. Estes elementos se constituiriam como desdobramentos da vinculação psíquica, social e biológica que unem os indivíduos de uma mesma família e estabeleceriam dinâmicas relacionais diversas, onde alguns desses elementos poderiam ser privilegiados no que define e caracteriza $\mathrm{o}$ vínculo familiar.

O relato das personagens da série de televisão, apesar de tratar-se de um casal fictício, serve como ponto de partida para empreendermos uma discussão reflexiva. Esta será iniciada a partir do processo de viabilização parental centrado em: "Como possibilitar a concretização do desejo de constituir uma família?". Questão que delimita alguns artifícios utilizados para contornar as limitações biológicas e permitir que a filiação se torne possível. Seguem-se como exemplos: filiações anteriores ao casal homossexual provenientes de relacionamentos heterossexuais; adoção por um dos(as) parceiros(as) do casal ou por ambos onde há permissão legal para este tipo de adoção; inseminação artificial; fertilização in vitro; barriga de aluguel; ou a coparentalidade, que é o compartilhamento parental na criação dos(as) filhos(as) entre casais de gays e lésbicas (Corrêa, 2012; Grossi, 2003).

Como podemos observar das descrições dos episódios, as personagens optaram pela gravidez a partir da inseminação artificial, cujo método é intrinsecamente dependente do doador, que pode ser selecionado em um banco de esperma(s) anônimo(s) ou pode ser alguém conhecido do casal e que aceite fazer a doação. Bette e Tina tentam encontrar o "doador perfeito", ou seja, aquele que favoreça o estabelecimento dos laços de parentesco e filiação com o futuro bebê, mais próximos dos vínculos biológicos.

De acordo com Hollekim et al. (2012), esta é uma estratégia utilizada por muitos casais de lésbicas que passam pela inseminação artificial e se justificaria pela tentativa, desses mesmos casais, em estabelecer um sentido de maior identificação familiar e naturalizar informalmente a relação entre as mães e o bebê que teria assim características que se assemelham biologicamente também à comãe. Alguns casais também se utilizam da técnica de Recepção de Óvulos da Parceira (ROPA), que se trata de um método de fertilização em que ambas as mães podem participar, sendo uma das parceiras responsável pelos óvulos que poderão gerar o embrião e a outra a que vai receber o embrião e passar pelo processo da gestação (Corrêa, 2012).

Outro ponto a ser destacado nessa escolha pelo doador é que ela seria orientada para aquele doador que não possui doenças sexualmente transmissíveis, assim como para aquele que apesar de doar (anonimamente ou não) não poderia reivindicar direitos legais sobre a criança. Assim, esta busca criteriosa pelo doador também serviria para assegurar ao casal de lésbicas maior controle e autonomia ao longo do processo de inseminação (Corrêa, 2012).

Percebemos a partir dessas estratégias o quanto o processo de parentalidade/filiação das personagens ainda está atrelado aos processos biológicos da repro- 
dução e podemos inferir que, alguns casais de lésbicas tentam se legitimar também através desses recursos que lhes são possíveis, diferentemente dos casais homoafetivos masculinos.

De acordo com Zambrano (2006), no Brasil há uma tendência maior nas mulheres lésbicas que querem constituir família em valorizarem a parentalidade através da procriação biológica, enquanto os homens recorrem à parentalidade social através da adoção. Se considerarmos o excesso de burocracia, a longa espera exigida durante o processo de adoção e as dificuldades adicionais para os casais homossexuais que muitas vezes têm que superar impedimentos de ordem moral (Cecílio, Scorsolini-Comin, \& Santos, 2013), para as mulheres lésbicas, o processo da gestação torna-se mais viável e acessível, tanto para aquelas que se utilizam da "fertilização caseira" com o semên de algum doador, quanto para aquelas que têm poder aquisitivo suficiente para arcar com as despesas dos procedimentos médicos exigidos pela reprodução assistida. Esta via de acesso à parentalidade, tanto quanto a adoção, não garante aos casais homoafetivos a realização imediata do desejo de serem pais/mães. Além disso, em ambos os casos estes casais estarão sujeitos às frustrações e angústias decorrentes de fatores provenientes de diversas instâncias sociais e que permeiam o exercício homoparental ao longo do desenvolvimento da criança. Nessa medida, vemos uma similaridade com os casais heterossexuais inférteis que também recorrem à reprodução assistida ou à adoção para realizarem o projeto parental.

A primazia do biológico, tomada como elemento constituinte na instituição familiar por muito tempo, acarreta o não reconhecimento daquilo que foge aos padrões heteronormativos instituídos no modelo tradicional de família (Corrêa, 2012). Essa hegemonia heteronormativa repercute na ilegitimidade da comãe como uma mãe verdadeira perante a sociedade. A necessidade de artifícios subjetivos e legais no reconhecimento da comaternidade está sujeita a esbarrar em constantes entraves que perpetuam a exclusão dessa mãe não biológica, mas que ainda assim estabelece um vínculo parental com a criança (Fonseca, 2008; Grossi, 2003). Fato este ilustrado pela personagem Bette que, ao saber da gravidez de Tina, insiste em participar da vida da criança e ao longo do desenvolvimento desta faz parte ativamente de seus cuidados e de sua educação.
Nesse contexto de exclusão a partir do que não é biologicamente reconhecido como família, o seriado também evidencia o não reconhecimento do casal lésbico por parte das famílias extensas de ambas as parceiras. A exemplo do pai de Bette que não reconhece a conjugalidade e a parentalidade dentro da família que as personagens estão tentando construir, muitos são os impasses enfrentados por esses casais. O suporte emocional da rede familiar é fornecido pelo grupo de amigos, no caso das personagens o grupo de amigas lésbicas, e estes laços afetivos, que não correspondem ao parentesco biológico, representam a rede de proteção e cuidados desse casal de lésbicas diante dos desafios enfrentados no exercício parental, situação que se faz mais presente nos estudos brasileiros (Medeiros, 2006; Moris, 2008).

A homoparentalidade, sendo construída pela via da adoção ou da inseminação artificial, introduz novos aspectos a serem problematizados dentro do processo de transmissão psíquica geracional e da consanguinidade na constituição dos laços familiares, gerando parâmetros novos e desafiadores, que podem ser repelidos, a despeito de serem duas mulheres/mães. $O$ que se dirá de dois homens/pais?

A família homoparental, seja de gays ou de lésbicas, estabelece, desde a sua origem, questionamentos acerca dos fundamentos constituintes da família tradicional nuclear heterossexual. Partindo-se de uma sexualidade sem fins procriativos que, todavia, reivindica direitos e se utiliza de técnicas reprodutivas para viabilizar a parentalidade/filiação homossexual, esta família tem sido contestada e/ou defendida sob diferentes pressupostos. Estes, tentam delimitar o conceito de família ora no sentido de perpetuar sua definição restringindo-a ao modelo nuclear/heterossexual, ora ampliando-o para incluir novas possibilidades, o desconhecido que exigirá novos constructos teóricos derivados de vivências e referenciais singulares.

\section{Categoria 2 - Parentalidade lésbica $x$ modelo heteronormativo}

Ao longo do relato sobre as personagens Bette e Tina, nos deparamos com um casal que, após um relacionamento, de sete anos resolve ampliar a família, de uma conjugalidade sem filhos para uma conjugalidade/parentalidade através da inseminação artificial. Quando pensamos na palavra artificial, que acompanha essa modalidade de procriação, temos em sua definição aquilo que não é natural, não espontâneo, 


\section{Dos Santos, Carine Valéria Mendes; Gomes, Isabel Cristina (2015).}

The L Word - Discussões EM TORNo da PaRENTAlidade léSbica

forçado, fingido, postiço (http://webdicionario.com). Essa adjetivação dada a esse processo, quando utilizada por casais homoafetivos e/ou casais hetero estéreis, carrega em si a essencialidade da contestação ao modelo tradicional instituído, provocando em todos os envolvidos a necessidade de criação de novos padrões relacionais.

Segundo Vilhena, Souza, Uziel, Zamora e Novaes (2011), o próprio termo homoparentalidade é considerado inadequado pela inexistência de um termo correspondente para as famílias de orientação heterossexual. A denominação específica para distinguir as famílias homoparentais carrega a ideia subjacente de que quando se fala em família remete-se ao que é considerado a família em sua acepção natural/heterossexual, na contrapartida, ao tratar do casal homossexual e seus filhos denominando-os de família homoparental, institui-se um lugar diferente e estigmatizante. Propõem, os autores, em vista dessa denominação considerada alienante, a utilização do termo família sempre no plural, o que leva em conta os diversos arranjos familiares existentes na atualidade.

Zambrano (2006) entende o uso do termo família homoparental como estratégico no sentido de dar visibilidade e existência discursiva a um tipo de família cada vez mais presente nas sociedades contemporâneas. Essa especificação possibilitada pelo uso do termo construiria espaços onde as demandas homoparentais poderiam ser problematizadas, além de favorecer um campo de luta político em torno das mesmas. Contrapondo esses argumentos que discutem a adequação, ou não, do termo homoparentalidade, entende-se neste artigo que a nomeação dessas famílias como homoparentais atua em benefício do reconhecimento da existência desse tipo de família. A utilização do termo poderia assim criar uma categoria denominativa capaz de fazer circular, a partir dos discursos proferidos em torno dela, os significados polissêmicos associados à homoparentalidade, seja por parte daqueles que a defendem ou daqueles que a criticam. Essa circulação a partir do discurso se daria por meio de enunciados produzidos pelas redes intersubjetivas que organizam e dão sentido a palavra do sujeito no grupo, a interdiscursividade, segundo Kaës (1994/2005). Portanto, a noção de pertencimento a um grupo, mesmo que minoritário, é essencial para o desenvolvimento, reconhecimento e fortalecimento de uma identidade.
Sob a égide construída em torno da família nuclear heterossexual, o referencial heteronormativo, servindo de modelo a ser seguido até hoje, tem marginalizado as famílias constituídas por casais homossexuais e seus filhos, ainda que as famílias homoparentais tentem se utilizar de processos biológicos ou subjetivos para legitimarem-se (Libson, 2010). Embora os casais homoafetivos possuam existência legal em muitos países e também no Brasil, ainda há muita controvérsia sobre a legitimação com respeito às famílias homoparentais. Os argumentos se baseiam ainda nas questões de gênero (crianças necessitarem da diferenciação sexual para poderem se desenvolver de forma saudável, sem comprometer sua identidade sexual), nos preconceitos existentes na sociedade e dos quais as crianças (filhos desses casais) estariam muito expostas e no maior risco dessas crianças se tornarem vítimas de abuso sexual (Gato e Fontaine, 2010).

Esses argumentos não se mostram condizentes com o que tem sido observado em pesquisas realizadas dentro desse contexto familiar (Gato e Fontaine, 2010) e refletem um viés preconceituoso que prejudica e retarda a consolidação da homoparentalidade como uma forma autêntica dentro das possibilidades do exercício parental. Em relação às investigações sobre a temática da homoparentalidade e das implicações para a criança a partir da inserção nesse tipo de configuração familiar, o número de pesquisas tem aumentado significativamente. Estes estudos, que se apoiam no discurso científico, tentam desmistificar preconceitos e construir conhecimentos a partir de relatos de vivências e de observações da realidade dessas novas famílias constituídas pelo casal homossexual e seus filhos. Nesse sentido, vale destacar alguns dados obtidos por Gato e Fontaine (2010):

1. A parentalidade homossexual não determina uma identidade de gênero contrária ao sexo biológico;

2. Nãohádiferenças significativasnodesenvolvimento psicossocial, afetivo e cognitivo de crianças criadas por casais homossexuais e heterossexuais;

3. Estereótipos de gênero são mais flexíveis em crianças criadas por casais homossexuais;

4. Crianças filhas de casais homossexuais têm a percepção de serem aceitas tanto quanto as outras crianças; 
5. Casais homossexuais se mostram afetuosos e buscam passar mais tempo de qualidade com seus filhos.

Almeida (2012), numa pesquisa de estudo de caso qualitativo, discute em profundidade a dinâmica de relacionamento numa família homoparental masculina com dois filhos adotivos. Acompanhados por mais tempo pela justiça, em função da homoafetividade e por terem aceitado adotar crianças com histórico de difícil adaptação (irmãos que já haviam sido devolvidos anteriormente), ambos os pais reclamavam do preconceito inicial vivido em todas as instâncias: família extensa, vizinhos e até eles próprios. Aos poucos, os meninos foram se adaptando ao modo de vida do casal, que era muito afetivo no trato com eles. O casal foi cuidadoso na escolha da escola e buscou ajuda psicológica para facilitar o período inicial de adaptação familiar.

Podemos inferir a partir do viés associado aos argumentos de contestação e aos de defesa em relação à homoparentalidade que seria ingênuo não pensar nas dificuldades, tanto para a criança quanto para o casal homossexual, enfrentadas pela própria configuração desse tipo de família, não obstante, é necessário reconhecer que muitos dos obstáculos em torno da legitimação dessas famílias são da ordem do preconceito e não da realidade.

Aqueles que caminham em busca da ampliação do que é ser família no sentido de englobar outras configurações familiares - construídas a partir do vínculo afetivo e não sob o primado do vínculo consanguíneo - preconizam que a existência dessas novas famílias não tem mais como ser negada. O que se pode fazer é auxiliar esses casais e seus filhos a estabelecerem um referencial próprio considerando as suas especificidades conjugais e parentais, referencial este que pode se apropriar de características do modelo heteronormativo, mas que também pode desconstruí-lo ou ampliá-lo de maneira a se adequar a novas dinâmicas relacionais (Libson, 2010).

\section{Discussão - É possível falar em um novo modelo familiar?}

Rodriguez e Gomes (2012), em sua pesquisa com casais gays, embora destaquem as características desse tipo de configuração familiar, como a ausência de papéis fixos, a inexistência de hierarquias e a circulação da liderança entre os membros, também reconhecem que não se pode ainda propor um mo- delo de família homoparental homogêneo e regulador. Em vista dessa indefinição, constatou-se que, no começo da série, para passar pelo processo da gestação, Tina abandona sua carreira profissional para se dedicar integralmente à maternidade, enquanto Bette fica como a provedora familiar. Essa definição de papéis que nos remete à família patriarcal - em que o homem era o único provedor do lar, enquanto a mulher era a responsável pelas atividades domésticas e pelos cuidados com as crianças (Borsa, \& Nunes, 2011) - nos faz refletir sobre o modo inicialmente assumido pelas personagens, quando decidem ter um filho, baseando-se no modelo heteronormativo de família. Prosseguindo, elas se veem num arranjo familiar reconstituído e depois, vão estruturando um modelo próprio de comaternidade.

Sobre a estruturação parental exercida a partir da comaternidade, vimos que na série as personagens assumiram referenciais denominativos diferenciados (mamy Ti e mamy Be) para introduzir na rotina da criança a existência e também a diferenciação entre as duas mães. Ao tratar da nominação e dos termos relativos ao parentesco, Grossi (2003) constrói a seguinte assertiva: "A nominação fala do lugar das pessoas no sistema de parentesco, portanto, de seu lugar social em uma dada cultura". (p. 277) Seguindo esse raciocínio, a identificação das duas personagens como "mamys", diferenciadas pela abreviação dos prenomes de cada uma é justificada pela anuência social no que diz respeito à ocupação de mais de um indivíduo em determinado lugar no sistema de parentesco (Grossi, 2003). Observa-se, portanto, na atuação das personagens o desejo de se constituírem como uma família, mas também, o desejo de encontrarem um modo de funcionamento mais conveniente às necessidades situacionais apresentadas ao longo do processo de constituição parento-filial.

Em decorrência disso, é possível erigir algumas questões que estão no cerne da construção parental por parte delas, tais como: Por que o casal resolve ter um bebê? Por que a operacionalização desse projeto se dá pela via da inseminação artificial, e consequentemente, pela tentativa de legitimar a família pelo vínculo consanguíneo? A escolha pela vinculação biológica com a criança não poria em relevo o desejo de dar continuidade ao legado geracional proveniente ainda dos referenciais heteronormativos?

De acordo com Bydlowski (1989), o desejo de ter um filho perpassaria os seguintes significados: o dese- 


\section{Dos Santos, Carine Valéria Mendes; Gomes, Isabel Cristina (2015). \\ The L Word - Discussões EM TORno da PARENTALIDAde lésbica}

jo de ser mãe, a perpetuação da espécie, a elaboração da feminilidade, as representações da maternidade e o lugar designado ao filho no inconsciente dos pais. Estes significados conscientes e inconscientes estão intrinsecamente implicados no desejo parental e, no caso das personagens, refletem-se na escolha pela inseminação artificial como modalidade de procriação.

A filiação psíquica, presa à realidade psíquica e intersubjetiva construída a partir das relações parento-filiais de uma família que não necessita de vinculação biológica para existir (Rodriguez, \& Gomes, 2012), ainda não se constitui totalmente como opção viável para o casal lésbico da série televisiva. Para Bette e Tina, a filiação psíquica (adoção, por parte de Bette, do filho gerado por Tina) é decorrente da vinculação biológica e é a partir do recurso da reprodução assistida que as personagens tentam dar continuidade ao legado geracional. Sobre a pré-história do sujeito no encadeamento geracional, Kaës (1993/2001), desenvolve a seguinte assertiva:

A subordinação ao grupo funda-se na inelutável rocha da realidade intersubjetiva como condição de existência do sujeito humano. O que é inelutável é que somos postos no mundo por mais de um outro, por mais de um sexo, e que nossa pré-história faz de cada um de nós, bem antes de nascermos, o sujeito de um conjunto intersubjetivo, cujos sujeitos nos têm e nos mantêm como servidores e herdeiros de seus "sonhos de desejos insatisfeitos", de seus recalcamentos e de suas renúncias, na malha de seus discursos, de suas fantasias e de suas histórias (Kaës, 1993/2001, p. 13).

Se as relações intersubjetivas entre gerações situam o sujeito como portador de uma herança psíquica peculiar a determinado grupo familiar, compreende-se que o sujeito está inserido em uma cadeia que o precede e que determina suas relações. Contudo, estar inserido nessa cadeia não subentende necessariamente um apassivamento subjetivo, mas sim, uma apropriação e atualização do legado geracional (Kaës, 2001). Nesse contexto, as personagens estão inseridas em cadeias geracionais que têm como referência predominante o modelo heteronormativo.
E mesmo que a conjugalidade e a parentalidade constituídas pelas personagens se configurem como um novo padrão sexual e familiar, isso não impede a continuidade do legado geracional.

A seletividade na escolha pelo doador com o intuito de validar uma identificação biológica entre o casal e o futuro bebê traz uma contradição implícita, diante do discurso propagado na atualidade acerca do vínculo afetivo como elemento constitutivo central nas novas configurações familiares. Por que, então, a vinculação biológica ainda é priorizada, em alguns casos? A despeito de toda seleção criteriosa por características que ratifiquem o vínculo entre o bebê\Angélica e a comãe Bette, a adoção jurídica para a legalização da comaternidade confronta o casal com o não reconhecimento do vínculo consanguíneo, e consequentemente, com a impossibilidade denegada pelas personagens.

A tentativa de contornar a limitação biológica por meio da inseminação artificial, em alguns casos, pode ser vista pela conjuntura social como um embuste que não alcança o propósito pretendido de constituir uma procriação alternativa para os casais homossexuais femininos. A despeito dos esforços e investimentos do casal, apenas o vínculo biológico da mãe que forneceu o material genético e/ou gestou foi reconhecido, o que forçou a comãe a recorrer à legitimação pela via da adoção unilateral ${ }^{5}$. Depreende-se desses fatores que, embora se apregoe a vinculação afetiva como elemento constituinte desse tipo de configuração familiar, na série televisiva, o vínculo unicamente afetivo não foi condição suficiente para o reconhecimento sociocultural desse grupo familiar.

O preconceito social e o introjetado pelo(s) indivíduo(s) enquanto minoria(s) tornam-se fatores determinantes na busca pela legitimação conjugal e parental à revelia dos padrões normativos enraizados na cultura e no psiquismo social. Assim, é possível pensar que para os casais homossexuais desejar constituir uma família torna-se fonte de muitas angústias e sofrimentos. Sobre o trabalho psíquico adicional na constituição da homoparentalidade, Passos (2010) destaca:

Penso que a diferença está no fato de que esse retorno ao lugar de origem na rede familial pode exigir um trabalho

5. Em casos semelhantes ao retratado na série televisiva norte-americana aqui analisada, segundo o Instituto Brasileiro de Direito de Família (2014), atualmente por meio da Adoção unilateral, que permite que o(a) parceiro(a) da mãe biológica adote o(a) filho(a) do outro sem que este seja destituído do poder familiar, alguns bebês estão sendo registrados em nome de duas mães. Nestes casos, as mães precisam comprovar tanto a união estável, como a participação de ambas as mães nos cuidados oferecidos à criança. 
adicional, que implica em lidar com as linhas de força entre a demanda afetiva pela "criação" de um filho e as dificuldades advindas, tanto das suas condições naturais de procriação, quanto das censuras e preconceitos que esse tipo de solicitação produz na sociedade (p. 73).

Muito se tem investigado sobre os efeitos psíquicos e emocionais suscitados nos "filhos da homoparentalidade", expressão aqui utilizada para enfatizar o caráter patologizante atribuído ao desenvolvimento de crianças que são cuidadas e educadas por casais homossexuais. Entretanto, mesmo com a desmistificação e despatologização dessa modalidade de parentalidade\filiação, a exclusão, presente e manifestada de diversas formas, torna-se um elemento premente nos processos de subjetivação do casal homossexual e seus filhos (Passos, 2010).

A validação do status de família, buscada por meio de artifícios biológicos e subjetivos, nos confronta com outra questão: Será que já se pode falar em um modelo de família homoparental? As personagens Bette e Tina evidenciam um contínuo em seu processo de construção parental, partindo do modelo heteronormativo herdado da lógica patriarcal, caminham para uma forma complexa que inclui uma nova modalidade de lugar e função na família - a comaternidade. Esta, no caso delas, envolverá uma dupla vinculação, pela via do biológico e da adoção.

Frente à necessidade de construção de modelos relacionais autênticos, as famílias homoparentais femininas, presas ainda à primazia dos vínculos de sangue, veem-se premidas pela inclusão de outros modos de vinculação em seu processo de legitimação legal. Assim, aspectos psíquicos intergeracionais e transgeracionais ${ }^{6}$ são atualizados e reelaborados na nova constituição parental.

Dentro dessa problemática, é necessário reconhecer que as diversas modalidades de viabilização parental trouxeram para os casais homoafetivos a possibilidade de construir referenciais próprios do que é ser família, como o exemplificado pelo relato apresentado sobre as personagens. A finalidade da análise interpretativa dessa série televisiva foi justa- mente a de demonstrar o processo de construção de novas formas de exercício parental, nas famílias homoparentais femininas, a partir da tradição.

\section{Considerações finais}

As novas configurações familiares da atualidade encerram muitas vezes à sua volta um paradoxo: o novo sendo vivido pela repetição do velho, da tradição. Nas famílias homoparentais observa-se um movimento que suplanta, aparentemente, a valorização dos laços consanguíneos pela instituição da filiação afetiva. Esse tipo de parentalidade encerra alguns dos dilemas contemporâneos e embates éticos que exigem da sociedade posicionamentos e condutas fundamentadas no respeito às liberdades individuais e aos direitos humanos.

A constituição e reconhecimento social, legal e afetivo da família homoparental traz em seu entorno demandas que dizem respeito à busca por adequação e aceitação social, bem como à incipiente construção de um referencial familiar que se prende às heranças geracionais e aos mecanismos de transmissão psíquica, ainda ligados ao modelo de família heteronormativo hegemônico. Os desafios estão presentes em todas as etapas do processo de constituição seja do par conjugal homossexual, seja da família homoparental.

A partir do que foi exposto, é possível pensar que, apesar das uniões homoafetivas representarem uma descontinuidade em relação ao padrão familiar heteronormativo, isto não quer dizer que o legado geracional não possa ser transmitido aos novos herdeiros e membros dessas novas famílias, pois a transmissão psíquica entre as gerações não é prerrogativa do vínculo biológico, mas dos vínculos de parentesco que estabelecem relações parento-filiais viabilizadas pela intersubjetividade psíquica. Cria-se, portanto, o desafio de se investigar qual a natureza do legado a ser transmitido dentro das famílias homoparentais. Todavia, a maioria dos estudos em torno da temática em questão estão ainda imersos em discussões sobre a legitimação e caracterização de referenciais desse arranjo familiar.

Para o desenvolvimento desse artigo, quando se empreendeu uma reflexão crítica acerca da parenta-

6. O conceito de transmissão psíquica intergeracional e transgeracional veiculado por esse artigo está em conformidade com o conceito desenvolvido por Golse (2003) que estabelece a distinção conceitual entre os dois tipos de transmissão, caracterizando a transmissão transgeracional como aquela que se dá em sentido descendente entre gerações que não estão em contato direto, a ligação e transmissão se dá pelo efeito do discurso propagado ao longo do tempo. Já a transmissão intergeracional se daria entre gerações que estabelecem contatos diretos e o sentido da transmissão se dá tanto dos pais para os filhos, como dos filhos para os pais. Nesse tipo de transmissão, os filhos receberiam os legados geracionais dos pais e a inclusão dos filhos na vida dos pais possibilitaria a construção de neoformações psíquicas. 


\section{Dos Santos, Carine Valéria Mendes; Gomes, Isabel Cristina (2015). \\ The L Word - Discussões EM torno da PaRentaliddate lésbica}

lidade lésbica, pensou-se na importância da televisão enquanto parte fundamental de complexos processos de veiculação e de produção de significações e sentidos, associados a modos de ser, de pensar, de conhecer o mundo e de se relacionar com a vida (Fischer, 2002). Compreendemos assim a série The L Word como um veículo mobilizador, social e cultural, a partir do cotidiano de casais homoafetivos femininos, no interjogo conjugal e parental.

Se considerarmos ainda a predominância da cultura heteronormativa, utilizando os recursos midiáticos como uma das formas de se fazer presente, esta série tem seu valor, pois traz à reflexão questões concernentes ao universo "lésbico", principalmente em se tratando da homoparentalidade. Situando o enredo na cidade de Los Angeles e refletindo aspectos sociais e culturais relacionados ao contexto homossexual, a série é apresentada em determinadas nuances que nos revelam uma amostra da vivência de um casal de personagens lésbicas que querem constituir uma família e exercer a parentalidade em meio às vicissitudes implicadas nessa escolha, consi-

\section{Referências}

Almeida, M. R. (2012). Os processos subjetivos no acolhimento e na adoção de crianças por casal homoafetivo: um estudo de caso (Tese de Doutorado). Instituto de Psicologia, Universidade de São Paulo, São Paulo.

Bardin, L. (2009). Análise de conteúdo. Lisboa: Edições 70. (Trabalho original publicado em 1977)

Borsa, J. C., \& Nunes, M.L.T. (2011). Aspectos psicossociais da parentalidade: o papel de homens e mulheres na família nuclear. Psicologia Argumento, 29(64), 31-39. Recuperado de http://www2.pucpr.br/reol/index.php/PA?ddl $1=4524 \& d d 99=$ pdf

Bydlowski, M. (1989). Désir d'enfant, désir de grossesse, évolution des pratiques de procréation. In: S. Lebovici, \& F. Weil-Halpern (Orgs.), Psychopathologie du bébé (pp. 57-65). Paris: PUF.

Butler, J. (2003). O parentesco é sempre tido como heterossexual? Cadernos Pagu, (21), 219-260. doi: 10.1590/S0104-83332003000200010

Campos, C. J. G. (2004). Método de análise de conteúdo: ferramenta para a análise de dados qualitativos no campo da saúde. Revista Brasileira de Enfermagem, 57(5), 611-614. doi: 10.1590/S0034-71672004000500019 derando as possibilidades oferecidas dentro da sociedade a qual as personagens fazem parte. Transpondo assim as situações representadas pelas personagens para a realidade de muitos casais homossexuais, utilizando-se um material lúdico à semelhança de um estudo de caso e levando-se em conta as diferenças culturais, foi possível refletir acerca de importantes questões sobre essa temática. Há muito a ser vencido, um novo a ser construído.

Os avanços do conhecimento nessa área, pelo menos na última década, são grandes, atestados pelo crescente número de estudos, pesquisas e publicações, discutindo basicamente as consequências para a criança originária desse tipo de família. Isso nos lembra, em épocas passadas, o preconceito frente aos filhos de pais separados e a quantidade de trabalhos que surgiram sobre o assunto. As famílias reconstituídas também forçaram o status vigente acerca da invencibilidade do modelo heteronormativo da família tradicional e ganharam reconhecimento legal e institucional com o tempo. É o mesmo que esperamos para as famílias homoparentais?

Cecílio, M. S., Scorsolini-Comin, F., \& Santos, M. A. (2013). Produção científica sobre adoção por casais homossexuais no contexto brasileiro. Estudos de Psicologia, 18(3), 507-516. doi: 10.1590/S1413-294X2013000300011

Corrêa, M. E. C. (2012). Duas mães? Mulheres lésbicas e maternidade (Tese de Doutorado). Faculdade de Saúde Pública, Universidade de São Paulo, São Paulo.

Fischerfos, R. M. B. (2002). O dispositivo pedagógico da mídia: modos de educar na (e pela) TV. Educação e Pesquisa, São Paulo, 28(1), 151-162. doi: 10.1590/S1517-97022002000100011

Fonseca C. (2008). Homoparentalidade: novas luzes sobreoparentesco. EstudosFeministas, 16(3),769-783. doi: 10.1590/S0104-026X2008000300003

Foster, D. W. (2001). Consideraciones sobre el estúdio de la heteronormatividad en la literatura latino -americana. Letras: Literatura e Autoritarismo, 22, 49-53. Recuperado de http://cascavel.ufsm. $\mathrm{br} /$ revistas/ojs-2.2.2/index.php/letras/article/ view/11823/7251\#

Gato, J., \& Fontaine, A. M. (2010). Desconstruindo preconceitos sobre a homoparentalidade. LES Online, 2(2), 14-21. Recuperado de 
http://www.lespt.org/lesonline/index.php?journal $=$ lo\&page $=$ article $\&$ op $=$ viewFile $\&$ pa $\operatorname{th}[]=34 \&$ path []$=33$

Golse, B. (2003). Sobre a psicotepia pais-bebê: narratividade, filiação e transmissão (I. Catão, trad.). São Paulo, SP: Casa do Psicólogo.

Goes, I. C. (2013). Conflitos conjugais e transmissão psíquica geracional: das histéricas de Freud à mulher atual. In T. Féres-Carneiro (Org.), Casal e família: transmissão, conflito e violência. (pp. 177- 189). São Paulo, SP: Casa do Psicólogo.

Grossi, M. P. (2003). Gênero e parentesco: famílias gays e lésbicas no Brasil. Cadernos Pagu, 21, 261280. doi: 10.1590/S0104-83332003000200011

Hollekim, R., Slaatten, H., \& Anderssen, N. (2012). A nationwide study of Norwegian beliefs about same-sex marriage and lesbian and gay parenthood. Sexuality Research and Social Policy, 9, 15-30. doi: 10.1007/s13178-011-0049-y

Homoparentalidade. (2014). In Wikipédia, a enciclopédia livre. Recuperado de https://pt.wikipedia. org/wiki/Homoparentalidade

Hozel, D. (2004). As implicações da parentalidade. In Solis-Ponton, L. (Org). Ser pai, ser mãe: parentalidade: um desafio para o terceiro milênio. (M. C. P. Silva, trad., pp. 47-51). São Paulo, SP: Casa do Psicólogo.

Instituto Brasileiro de Direito de Família (2014). Justiça do Rio reconhece dupla maternidade. Recuperado de http://www.ibdfam.org.br/noticias/5255/ Justi\%C3\%A7a\%20do\%20Rio\%20reconhece\%20 dupla\%20maternidade

Kaës, R., (2001). O sujeito da herança. In R. Kaës, H. Faimberg, M. Enriquez, \& J. J. Baranes, Transmissão da vida psíquica entre gerações (C. Berliner, trad., pp. 9-25). São Paulo, SP: Casa do Psicólogo. (Originalmente publicado em 1993)

Kaës, R. (2005). La palabra y el vínculo: procesos asociativos en los grupos (M. Segoviano, trad.). Buenos Aires, Argentina: Amorrortu. (Originalmente publicado em 1994)

Libson, M. (2010). Hay tantas maneras de no ser: derechos lésbicos-gays y reconocimiento de los contextos familiares. Sexualidad, Salud y Sociedad, 6, 105-126. Recuperado de http://redalyc.uaemex.mx/src/inicio/ArtPdfRed.jsp?iCve $=293322071006$

Medeiros, C. P. (2006). "Uma família de mulheres": ensaio etnográfico sobre homoparentalidade na periferia de São Paulo. Estudos Feministas, 14(2), 535-547. Recuperado de http://www.scielo.br/ $\mathrm{pdf} / \mathrm{ref} / \mathrm{v} 14 \mathrm{n} 2 / \mathrm{al} 3 \mathrm{v} 14 \mathrm{n} 2 . \mathrm{pdf}$

Miranda, F. F. F. (2010). Heteronormatividade: uma leitura sobre construção e implicações na publicidade. Fragmentos de Cultura, 20(1/2), 81-94. Recuperado de http://seer.ucg.br/index.php/ fragmentos/article/viewFile/1314/898

Moris, V. L. (2008). Preciso te contar? Paternidade homoafetiva e a revelação para os filhos (Tese de Doutorado). Programa de Pós-graduação em Psicologia Clínica, Pontifícia Universidade Católica de São Paulo, São Paulo.

Noda, F. S. (2005). Famílias de mães homossexuais: relatos das mães (Dissertação de Mestrado). Programa de Pós-graduação em Psicologia Clínica, Pontifícia Universidade Católica, São Paulo, São Paulo.

Passos, M. C. (2005). Homoparentalidade: uma entre outras formas de ser família. Psicologia Clinica, 17(2), 31-40. doi: 10.1590/S010356652005000200003

Passos, M. C. (2010). Os filhos da homoparentalidade: elementos para pensar o processo de subjetivação. In T. Féres-Carneiro (Org.), Casal e família: permanências e rupturas (pp. 25-39). São Paulo, SP: Casa do Psicólogo.

Rios, M. G., \& Gomes, I. C. (2009). Casamento contemporâneo: revisão de literatura acerca da opção por não ter filhos. Estudos de Piscologia, 26(2), 215-225. doi: 10.1590/S0103-166X2009000200009

Rodriguez, B.C., \& Gomes, I. C. (2012). Novas formas de parentalidade: do modelo tradicional à homoparentalidade. Boletim de Psicologia, 62(136), 29-36. Recuperado de http://pepsic.bvsalud.org/scielo. php?pid=S0006-59432012000100004\&script=sci_arttext

Rodriguez, B. C., \& Paiva, M. L. S. C. (2009). Um estudo sobre o exercício da parentalidade em contexto homoparental. Vínculo: Revista do NESME, 1(6), 13-25. Recuperado de http://redalyc.uaemex. $\mathrm{mx} / \mathrm{pdf} / 1394 / 139412684003 . p d f$

Roudinesco, E. (2003). A família do futuro. In E. Roudinesco, A família em desordem (A. Telles, trad., pp.84-92). Rio de Janeiro, RJ: Jorge Zahar.

The L Word (2012). In Wikipédia, a enciclopédia livre. Recuperado de https://pt.wikipedia.org/wiki/ The_L_Word 
Dos Santos, Carine Valéria Mendes; Gomes, Isabel Cristina (2015).

The L Word - Discussões Em torno da PaRentalidade lésbica

Vilhena, J., Souza, A. C. B., Uziel, A. P., Zamora, M. H., \& Novaes, J. V. (2011). Que família? Provocações a partir da homoparentalidade. Revista Mal-estar e Subjetividade, 9(4), 1639-1658. Recuperado de http://pepsic.bvsalud.org/pdf/malestar/ v1ln4/14.pdf

WebDicionário: dicionário on-line de português. Recuperado de http://webdicionario.com

Zambrano, E. (2006). Parentalidades “impensáveis”: pais/mães homossexuais, travestis e transexuais. Horizontes Antropológicos, 12(26), 123-147. doi: 10.1590/S0104-71832006000200006

Zornig, S. M. A. (2010). Transmissão psíquica: uma via de mão dupla? In T. Féres-Carneiro (org.), Casal e família: permanências e rupturas (pp.25-39). São Paulo: Casa do Psicólogo.

\section{Carine Valéria Mendes dos Santos}

Universidade de São Paulo, mestre em Psicologia Clínica pelo Instituto de Psicologia. São Paulo - SP. Brasil.

Endereço: Rua Prof. Manoel Coelho Neto, $n^{\circ}$ 151, Apto. 302, Jatiúca. CEP: 57036-710.

E-mail: carinevmendes@gmail.com

\section{Isabel Cristina Gomes}

Universidade de São Paulo, Professora Titular do Departamento de Psicologia Clínica do Instituto de Psicologia. São Paulo - SP. Brasil.

Endereço: Rua Cerro Cora, $n^{\circ}$ 792, Apto. 33, Alto da Lapa. CEP: 05061-100.

E-mail: isagomes@usp.br

\section{Endereço para envio de correspondência: \\ Endereço para envio de correspondência: \\ Rua dos Buritis, no 401, Apto. 43, Vila Parque \\ Jabaquara. CEP: 04321-001. São Paulo - SP. Brasil.}

Recebido: $10 / 01 / 2014$

Aprovado: 04/12/2015

Received: 01/10/2014

Approved: 12/04/2015

Recibido: $10 / 01 / 2014$

Aceptado: 04/12/2015

Como citar: Santos, C. V. M., \& Gomes, I. C. The LWord: discussões em torno da parentalidade lésbica. Psicologia: Ciência e Profissão, 36(1): 101-115. doi:10.1590/1982-3703000092014

How to cite: Santos, C. V. M., \& Gomes, I. C. The LWord: Debats on lesbian parenting. Psicologia: Ciência e Profissão, 36(1): 101-115. doi:10.1590/1982-3703000092014

Cómo citar: Santos, C. V. M., \& Gomes, I. C. The L Word: Discusiones en torno a la parentalidad lésbica Psicologia: Ciência e Profissão, 36(1): 101-115. doi:10.1590/1982-3703000092014 